\title{
A CHEMOMETRIC APPROACH TO THE INFLUENCE OF THE SYNTHESIS PARAMETERS ON THE OPTICAL RESPONSE OF GOLD NANOPARTICLES AND STUDY OF THEIR ELECTROPHORETIC DEPOSITION ON SILICON
}

\author{
RENZO MILESI L. ${ }^{1}$, EMILIO NAVARRETE S. ${ }^{1}$, JAVIER ROMÁN S. ${ }^{1}$, VÍCTOR ROJAS C. ${ }^{1}$, RODRIGO HENRÍQUEZ \\ N. ${ }^{1}$, RICARDO SCHREBLER G. ${ }^{1}$, RICARDO CÓRDOVA, EDUARDO C. MUÑOZ ${ }^{1}$
}

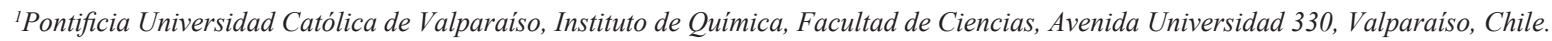

\begin{abstract}
This study describes gold nanoparticle synthesis in an aqueous solution by reducing tetrachloroauric acid $\left(\mathrm{HAuCl}_{4}\right)$, using sodium citrate as a reducing agent. Synthesis was optimized through an experimental design, and particle characterization was obtained through UV-Vis spectroscopy. In a first stage, a factorial design was conducted to establish the significance of the variables used in the synthesis, i.e. reducer concentration, temperature, stirring rate. In the second stage, the obtained nanoparticles were positioned on a silicon p-type substrate through electrophoretic deposition. The modified substrates were characterized by means of reflectance measurements and their morphology using transmission electron microscopy (TEM) and atomic force microscopy (AFM). Finally, a brief discussion was carried out concerning the sizes of the determined nanoparticles based on a model taken from the literature that relates maximum absorption with the nanoparticle diameter, comparing these with the sizes obtained through AFM and TEM observation.
\end{abstract}

Keywords: Gold nanoparticles, AFM, TEM, experimental design, electrophoretic deposition.

\section{INTRODUCTION}

Nanotechnology has grown as an area of study and development over the last 50 years. This is due in part to the fact that controlling the physicalchemical properties of nanoparticles allows them to be used in diverse fields, such as medicine, optics, physics, biology and chemistry ${ }^{1-3}$. Furthermore, these properties can be modulated to change the size of the nanoparticles without needing to change their material composition. Currently, important advances have been made in synthesizing high-quality nanostructures ${ }^{4}$, particularly metallic nanoparticles ${ }^{5,6}$ and semiconductor nanocrystals 7 . Within the range of metallic nanomaterials, gold nanoparticles (AuNPs) are of great interest, both for their properties as well as for their applications, which include i) chemical properties, e.g. molecular recognition ${ }^{8,9}$, reactivity ${ }^{10,11}$; ii) biological properties, e.g. assembly of DNA-AuNPs, conjugation of AuNPs with cancerous cells for detection ${ }^{12,13}$; iii) physical properties e.g. optical applications ${ }^{14}$ and iv) electrochemical properties ${ }^{15}$. One of the current applications of interest for AuNPs is the field of biosensors for the detection of distinct biological species, such as glucose ${ }^{16,17}$, enzymes ${ }^{18}$, peroxidase ${ }^{19}$, DNA ${ }^{20}$, among others.

However, before application can take place, the nanoparticles must be functionally integrated in the device, which requires controlling their interactions with other materials and their spatial organization. In this context, one alternative is to deposit the AuNPs on a conductor or semiconductor substrate, a process that must meet certain criteria, such as irreversibility of the deposition process ${ }^{21}$, stability, and a high nuclear density. The deposition of AuNPs can be carried out using different methods. For example, the electrophoretic deposition method (EPD) ${ }^{22,23}$, uses an external uniform electric field that conducts the suspended particles from the dissolution toward substrate surface. Traditionally, AuNPs can be obtained both from organic and aqueous media. In the former case, this can be carried out using gold halides, e.g. $\mathrm{AuCl}$ and $\mathrm{AuBr}$, in the presence of alkylamines ${ }^{24}$. On the other hand, aqueous phase synthesis is achieved mainly through the reduction of tetrachloroauric acid $\left(\mathrm{HAuCl}_{4}\right)$ with sodium citrate $\left(\mathrm{Na}_{3} \mathrm{C}_{6} \mathrm{H}_{5} \mathrm{O}_{7}\right)^{25-27}$. The sodium citrate allows for the control of nanoparticle size, acting as a stabilizing agent. This generates the dissolution of colloidal AuNPs as a result of the surface charges adopted by both the citrate particles and the AuNPs. The surface charge can be obtained by (1) ion adsorption according to the Paneth-Fajans rule ${ }^{28-30}$, or (2) through a surface dissociation process ${ }^{31}$. The reduction of ionic force leads to an increase in the Debye length of the double layer around the particles, which then stabilizes the colloids according to DLVO theory ${ }^{32}$. By modulating the size of the AuNPs, it is possible to control the synthesis conditions, i.e. the use of stabilizing agents, temperature, $\mathrm{pH}$, ionic strength, reaction time, molar ratio of the reaction precursors, which creates a significant number of experiments. For this reason, experimental chemometric design strategies are an important statistical tool that allows researchers to know the influence and interaction of experimental variables in relation to an interesting response, allowing them to optimize the process with minimal experiments ${ }^{33-35}$. In view of the above, the objective of this work is to study the influence of the AuNPs synthesis variables through the application of experimental design in order to later deposit them on silicon substrates and characterize them according their reflectance and morphology.

\section{EXPERIMENTAL SECTION}

\subsection{Experimental Design Construction}

In this stage, an experimental matrix was created using a $2^{3}$ factorial design, using the following parameters as experimental variables: i) concentration of reducing agent; ii) temperature; iii) stirring rate as shown in Table I. The concentration of $\mathrm{HAuCl}_{4}$ used in each experiment was kept at a constant value of $5.0 \mathrm{mM}$.

Table I: AuNPs Synthesis Variables

\begin{tabular}{|c|c|c|c|}
\hline Experiment & $\begin{array}{c}\text { Sodium Citrate } \\
\text { Concentration } \\
(\mathrm{mM})\end{array}$ & $\begin{array}{c}\text { Temperature } \\
\left({ }^{\circ} \mathrm{C}\right)\end{array}$ & $\begin{array}{c}\text { Stirring Rate } \\
(\mathrm{rpm})\end{array}$ \\
\hline Maximum value & 15.40 & 110 & 1000 \\
\hline Central Value & 8.40 & 100 & 950 \\
\hline Minimum Value & 1.40 & 90 & 900 \\
\hline
\end{tabular}

Depending on the values of the experiment matrix, synthesis of the AuNPs was carried out in two phases: i) the dissolution of $\mathrm{HAuCl}_{4}$ was maintained with the corresponding stirring rate and temperature and ii) adding the reducing agent to the experiment at the corresponding temperature. All experiments were carried out for a constant time of 20 minutes following the process of precursor mixing. After this time, the AuNPs were stored at $4^{\circ} \mathrm{C}$ for their subsequent characterization.

\subsection{Optical and size distribution characterization of AuNPs} suspension

The spectral absorbance and reflectance of the AuNPs were obtained using a Shimadzu UV-2600 spectrophotometer between 450 and $600 \mathrm{~nm}$. In the case of the optical reflectance measurements, an integrating sphere was coupled. AuNPs size was determined by a Transmission Electron Microscope, TEM, model JEOL JEM-1010 operated to $100 \mathrm{kV}$. Samples were dispersed in water and subjected to ultrasound. Subsequently, a drop of each treated sample was positioned on a copper grid with a carbon film, cleaned, and dried under a plasma flow.

\subsection{AuNPs deposited on Silicon}

The following procedure was employed when positioning the AuNPs on silicon substrates: The electrodes used for positioning the AuNPs were p-Si 
(100) monocrystalline with resistivity between 0.1 and $3 \Omega \mathrm{cm}\left(\mathrm{N}_{\mathrm{D}}=5 \times 10^{15}\right.$ $\mathrm{cm}^{-3}$ ), doped with boron, with a $500-550 \mu \mathrm{m}$ thickness and Polished/Etched surfaces (Silicon Valley Microelectronics, CA, USA). The silicon wafer was cut into rectangles $\left(3.0 \times 1.0 \mathrm{~cm}^{2}\right)$, which were first degreased in boiling acetone for 10 minutes. The electrodes were then treated with the following elements in sequential order: A 10-minute ultrasound in acetone, ethanol and water. They were later treated for 10 minutes with a mixture of $\mathrm{H}_{2} \mathrm{SO}_{4}: \mathrm{H}_{2} \mathrm{O}_{2}$ $3: 1$ at $80{ }^{\circ} \mathrm{C}$, in order to eliminate any trace of heavy metals or organic species. Later, the oxide film was chemically removed using a $2 \mathrm{M}$ HF solution for 2 minutes, after which the electrodes were thoroughly rinsed with ultra-pure water. The ohmic contact was made on the rough face. Once the electrode cleaning treatment was complete, these were covered with an isolating tape that defined the exposure area of the silicon electrode $\left(0.283 \mathrm{~cm}^{2}\right)$. Before every experiment, each electrode was submerged in a HF 2 M solution for two minutes, to ensure that the surface was smooth and atomically finished in hydrogen. For each measurement, a new p-Si (100) electrode was used, in order to maintain the same initial conditions and thus observe reproducibility in the obtained results. A two-electrode electrochemical cell was used to deposit the AuNPs, i.e., silicon p-type as the working electrode and graphite as the auxiliary electrode, both immersed in the colloidal dissolution. Using a DYME stabilized power supply, a potential of $40.0 \mathrm{~V}$ was applied between both electrodes. Deposition times used were 60,300 and 600 seconds.

\subsection{Characterization of AuNPs deposited on Silicon.}

The AuNPs deposited on silicon were morphologically and optically characterized. Morphological characterization was carried out using a Nanoscope IIIa model atomic force microscope, using tapping mode, for which a silicon tip was used along with a resonance frequency between $200-400$ $\mathrm{KHz}$ and a radius of curvature between 5 and $10 \mathrm{~nm}$. The optical reflectance measurements (both diffuse and specular) coupled with a integrating sphere. This study was carried out using a range between 200 and $1000 \mathrm{~nm}$.

\section{RESULTS AND DISCUSSION}

\subsection{Experimental Design Construction}

In Table II, the conditions in which the experiments were carried out are shown, taking into consideration the criteria established in the experimental section. Based on this, 12 experiments were carried out, wherein 4 center points were included, which were necessary to calculate experimental error. In addition, after their synthesis, the AuNPs were characterized using UV-Vis absorption spectroscopy, finding the maximum absorption wavelengths, $\lambda_{\max }$, (Figure not included). These values are included in Table II.

Table II: Experimental matrix, maximum absorption wavelength $\lambda_{\max }$ and diameter of the AuNPs estimated through equation (1).

\begin{tabular}{|c|c|c|c|c|c|}
\hline Exp. & $\begin{array}{c}\text { Sodium } \\
\text { Citrate } \\
\text { Concentration } \\
(\mathrm{mM})\end{array}$ & $\begin{array}{c}\text { Temperature } \\
\left({ }^{\circ} \mathrm{C}\right)\end{array}$ & $\begin{array}{c}\text { Stirring } \\
\text { rate } \\
(\mathrm{rpm})\end{array}$ & $\begin{array}{c}\lambda_{\max } \\
(\mathrm{nm})\end{array}$ & $\begin{array}{c}\text { *AuNPs } \\
\text { Diameter } \\
(\mathrm{nm})\end{array}$ \\
\hline 1 & 15.4 & 110 & 1000 & 522 & 20 \\
\hline 2 & 15.4 & 90 & 900 & 527 & 38 \\
\hline 3 & 15.4 & 90 & 1000 & 527 & 38 \\
\hline 4 & 15.4 & 110 & 900 & 528 & 41 \\
\hline 5 & 14.0 & 90 & 900 & 538 & 64 \\
\hline 6 & 14.0 & 90 & 1000 & 534 & 56 \\
\hline 7 & 14.0 & 110 & 900 & 533 & 54 \\
\hline 8 & 14.0 & 110 & 1000 & 537 & 62 \\
\hline 9 & 8.4 & 100 & 950 & 531 & 49 \\
\hline 10 & 8.4 & 100 & 950 & 529 & 44 \\
\hline 11 & 8.4 & 100 & 950 & 531 & 49 \\
\hline 12 & 8.4 & 100 & 950 & 531 & 49 \\
\hline
\end{tabular}

*according to the equation (1)

According to the maximum absorbance values, and using bibliographical information, it is possible to estimate the size of the AuNPs. In this contest, W. Haiss and his collaborators ${ }^{36}$, report that AuNPs with sizes on the order of
$20 \mathrm{~nm}$ exhibit maximum intensities and a wavelength close to $520 \mathrm{~nm}$. The authors observe that an increase in size leads to a shift in wavelength towards higher values, e.g. AuNPs measuring $80 \mathrm{~nm}$ have a maximum absorption of $550 \mathrm{~nm}$. Taking this into account, it can be deduced that AuNPs synthesized according to the experimental matrix have sizes between 20 and $64 \mathrm{~nm}$ in diameter. The authors propose the following empirical equation, which relates the absorbance maxima with the nanoparticle diameter:

$$
d=\frac{\ln \left(\frac{\lambda-\lambda_{0}}{L_{1}}\right)}{L_{2}}
$$

Where $d$ represents the nanoparticle diameter, is maximum absorbance, $\lambda_{0}$ corresponds to the base value of maximum absorbance peak wavelength and $\mathrm{L}_{1}$ and $\mathrm{L}_{2}$ are the values that result from adjusting the equation (6.53 and 0.0216 respectively). According to the results shown in Table II, a statistical analysis was made of the observed response in $\lambda_{\text {max }}$, i.e. AuNPs diameter, it was possible to determine the influence associated with the variables of the AuNPs synthesis process. Statgraphics software, a powerful data analysis tool that combines analytic procedures with interactive graphics to provide an integrated analytic environment, was used to carry out this analysis. Figure 1 shows a Pareto chart obtained through the program, which reflects predominant and significant variables in the studied process.

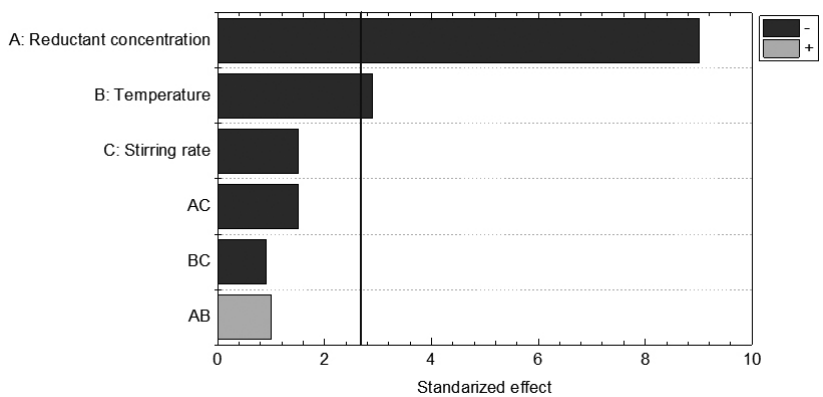

Figure 1: Standardized Pareto chart for the maximum absorption wavelength response.

In Figure 1, it is possible to observe the variables of the synthesis process and their respective interactions on the $\mathrm{Y}$ axis. On the other hand, the standardized effect axis shows a line with a value of approximately 2.65 , which corresponds to the Durbin-Watson statistic, which allows for the detection of a significant correlation, and also acts as a limit predictor of the significance of a variable or its interactions. For this experiment design, the significant variables in the synthesis process were reductant concentration and stirring rate; temperature and interactions between variables were not significant. On the other hand, each variable and its interactions have different effects on the response, i.e. negative $(-)$ or positive $(+)$. A positive effect means that an increase in the variable or interaction produces an increase in the value of the response, $\lambda$ The contrary occurs if this effect is negative, i.e., an increase in the variable produces a decrease in the value of the observed response. Consequently, an increase in the value of the significant variables, e.g. reductant concentration and temperature, give rise to a shift in the absorption peaks to lower wavelength values, which entails a reduction in AuNPs size. The decrease of the $\lambda_{\text {max }}$ value generated by increasing the concentration of the reducing agent in the studied response is of particular relevance. There exists a difference to the order of 10 $\mathrm{nm}$ in the $\lambda_{\max }$ response between the extreme values of this synthesis variable. From a physical-chemical point of view, the reducing agent influences the generation of particle growth nuclei. Once the sodium citrate interacts with the gold (III), it is reduced, generating the nanoparticle. Thus, the higher the sodium citrate concentration in the solution, the greater the quantity of growth nuclei, preventing agglomeration and thus smaller AuNPs.

On the other hand, temperature acts as a reaction initiator (control by activation). This delivers the energy required to achieve the reaction. A higher temperature implies more energy transfer in heat form to the system and favorable generation of AuNPs. Additionally, an increase in temperature favors the dissociation process of the dissolution precursors, i.e., sodium citrate in its $\mathrm{Na}^{+}$y $_{3} \mathrm{H}_{5} \mathrm{O}(\mathrm{COO})_{3}{ }^{3-}$ ions, favoring the $\mathrm{Au}$ (III)/ sodium citrate interaction. At higher temperatures, there is higher interaction and more growth nuclei. The aforementioned is in accordance with the significance of both variables upon 
the studied response.

Although stirring rate does not significantly affect the synthesis process, the possibility exists that using agitation in a "turbulent" regimen could generate smaller nanoparticles, due to the fact that the stirring process would increase collisions between the particles and container walls, impeding agglomeration. On the other hand, normal agitation would only help to homogenize the reaction mix.

The significance of the variables is detailed in Table III of the supplementary material through variance analysis. These results can be contrasted using a variance analysis of the statistical model, since the two individual variables have a P-value lower than 0.05 , comparing their mean square against an estimated experimental error, which indicates that they are significantly different than zero with a confidence level of $95 \%$. According to the data in this Table, the experimental data are linear, since the R-square of the model has a value close to $95 \%$. The aforementioned is of the utmost importance since through the presented data it is possible to predict future responses of other reducing agent concentration values, temperature and agitation speed, in order to facilitate synthesis of AuNPs.

Pursuant to the P-value results of Table III and the Pareto diagram in Figure 1, an equation was constructed that takes the significant parameters involved in each of the studied responses into account. With this, one can expect to be able to predict the value of $\lambda$ using the reductant concentration values, temperature and agitation speed (within the range of work proposed in this research). Therefore, the equation for $\lambda_{a b s}$ is now as follows:

$\lambda_{A B S}=530.667-4.75 \cdot X_{1}-1.5 \cdot X_{2}+0.5 \cdot X_{1} \cdot X_{2}-0.75 \cdot X_{1} \cdot X_{3}-0.5 \cdot X_{2} \cdot X_{3}$

Where $X_{1}, X_{2}$ and $X_{3}$ represent the variables reductant concentration, temperature and stirring rate, respectively. This equation represents the relation that exists between each significant variable and the response of interest, including the interactions between the parameters included in this study.

After evaluating the equation (2) with the values of the synthesis variables, it is possible to obtain the predicted values for the maximum absorbance wavelength. Next, Table $\mathrm{V}$ details the values observed experimentally along with these values, which were predicted by the model.

Table V: Observed results vs. values adjusted by STATSGRAPHIC for the absorption response.

\begin{tabular}{|c|c|c|c|c|}
\hline Experiment & $\begin{array}{c}\text { Experimental } \\
\text { values / nm }\end{array}$ & $\begin{array}{c}\text { Adjusted } \\
\text { Values }\end{array}$ & $\begin{array}{c}\text { Mean } \\
\text { Confidence } \\
\text { Interval below } \\
95 \%\end{array}$ & $\begin{array}{c}\text { Mean } \\
\text { Confidence } \\
\text { Interval } \\
\text { above } 95 \%\end{array}$ \\
\hline 1 & 522 & 522,917 & 519,41 & 526,424 \\
\hline 2 & 527 & 527,917 & 524,41 & 531,424 \\
\hline 3 & 527 & 525,917 & 522,41 & 529,424 \\
\hline 4 & 528 & 526,917 & 523,41 & 530,424 \\
\hline 5 & 538 & 536,917 & 533,41 & 540,424 \\
\hline 6 & 534 & 532,914 & 529,41 & 536,424 \\
\hline 7 & 533 & 533,917 & 530,41 & 537,424 \\
\hline 8 & 537 & 537,917 & 534,41 & 541,424 \\
\hline 9 & 531 & 530,667 & 529,558 & 531,776 \\
\hline 10 & 529 & 530,667 & 529,558 & 531,776 \\
\hline 11 & 531 & 530,667 & 529,558 & 531,776 \\
\hline 12 & 531 & 530,667 & 529,558 & 531,776 \\
\hline $\begin{array}{c}\text { Average } \\
4 \text { central } \\
\text { points }\end{array}$ & $\mathbf{5 3 0 , 5}$ & $\mathbf{5 3 0 , 7}$ & & \\
\hline & & & & \\
\hline
\end{tabular}

According to Table $\mathrm{V}$, the average of the center points is very close to the experimental values thanks to the linearity of the experiment design, which suggests additional adjustments are not necessary. This is validated with the values of the residuals that don't exceed the standard error of $1.49 \%$.

Figure 2 shows the TEM micrographs of the nanoparticles prepared at different times. The size of the nanoparticles clearly increases as the reaction time is increased. Additionally, although spherical shapes can be observed other complex shapes are present with larger aspect ratios. However, the spherical shaped particles are more abundant.

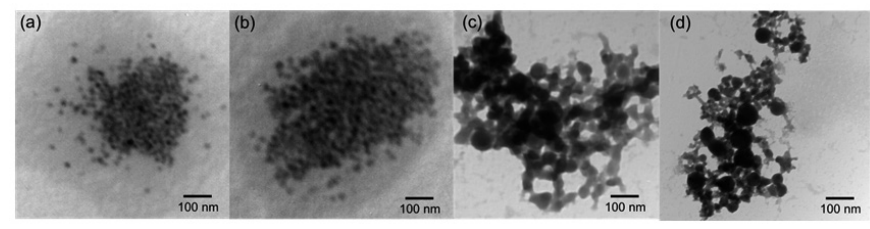

Figure 2: Transmission electron micrographs of gold nanoparticles obtained by citrate reduction synthesized under different experimental conditions shown in Table II: (a) y (b) Experiment 1; (c) y (d) Experiment 5.

According to Figure 2, AuNPs reach different sizes as function of the reaction time. The mean diameter increases as the reaction time is increased. Particles obtained from experiment 1 exhibits a more symetrical distribution compared with AuNPs obtained from experiment 5. The size distribution of the nanoparticles obtained from a set of TEM microphotographs is shown in Figure 3 .
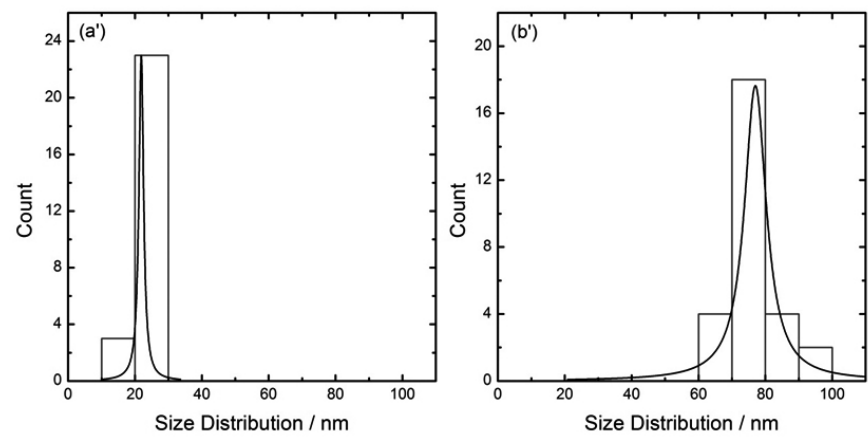

Figure 3: Size distributions for the AuNPs prepared with citrate reduction synthesized under different experimental conditions shown in Table II. (a') Experiment 1; (b') Experiment 5. The curve is a Gaussian function used to approximate the histogram.

In Figure 3 the histogram (a') corresponds to AuNPs prepared under experimental conditions depicted in Table II (sodium citrate concentration, temperature and stirring rate $15.4 \mathrm{mM}, 110{ }^{\circ} \mathrm{C}$ and $1000 \mathrm{rpm}$, respectively). In these conditions the mean diameter of the AuNPs was $22 \mathrm{~nm}$. On the other hand, in Figure 3 (b') when the AuNPs were prepared under conditions of experiment 5 (sodium citrate concentration, temperature and stirring rate 14.0 $\mathrm{mM}, 90{ }^{\circ} \mathrm{C}$ and $900 \mathrm{rpm}$, respectively) reached a mean diameter of $77 \mathrm{~nm}$ approximately. These size values are in agreement with those estimated by equation (1) considering the maximum absorption wavelenght presented in Table II.

3.2 AuNPs deposited on Silicon substrates: optical and morphological characterization

Once the gold nanoparticles were obtained, their positioning was carried out on silicon p-type substrates according to the methodology described in the experimental section. After this procedure, an optical characterization was carried out using reflectance spectroscopy (both diffuse and specular). The results can be observed in Figure 4:

In Figure 4, it can be observe that when the substrate is modified with AuNPs, the diffuse reflectance increases and the specular reflectance decreases. As observed in Figure 4a), the diffuse reflectance increases from $20 \%$ for the substrate after the cleaning treatment, to the order of $50 \%$ when it is modified, which considers an increase in the roughness of the substrate. In turn, Figure $4 \mathrm{~b}$ shows a decrease in specular reflectance, in accordance with the morphology of the $\mathrm{p}-\mathrm{Si}$. A Si-H termination produces smooth and brilliant surfaces, i.e., with a high specular component. The growth of silicon monoxide (p-Si-O) causes more opaque surfaces. Both reflectances show 2 characteristic silicon peaks, one at $270 \mathrm{~nm}$ and the other at $360 \mathrm{~nm}$ approximately. This phenomenon has been observed by other authors ${ }^{37}$, which reported that the differential reflectance decreased as a function of the thickness of the oxide 
that had formed on the substrate. When the p-Si was modified with AuNPs (p-Si/AuNPs), the specular reflectance diminishes accordingly (Figure $4 \mathrm{~b}$ ), increasing its diffuse component (Figure 4a). Other authors have achieved similar results with the deposition of AuNPs using alternative methods ${ }^{38}$. Morphological characterization of the AuNPs deposited on p-Si was carried out using AFM microscopy, for those obtained nanoparticles that would be bigger and smaller, Exp. 1 and Exp. 5 respectively, according to Table II. The results are shown in Figure 5:

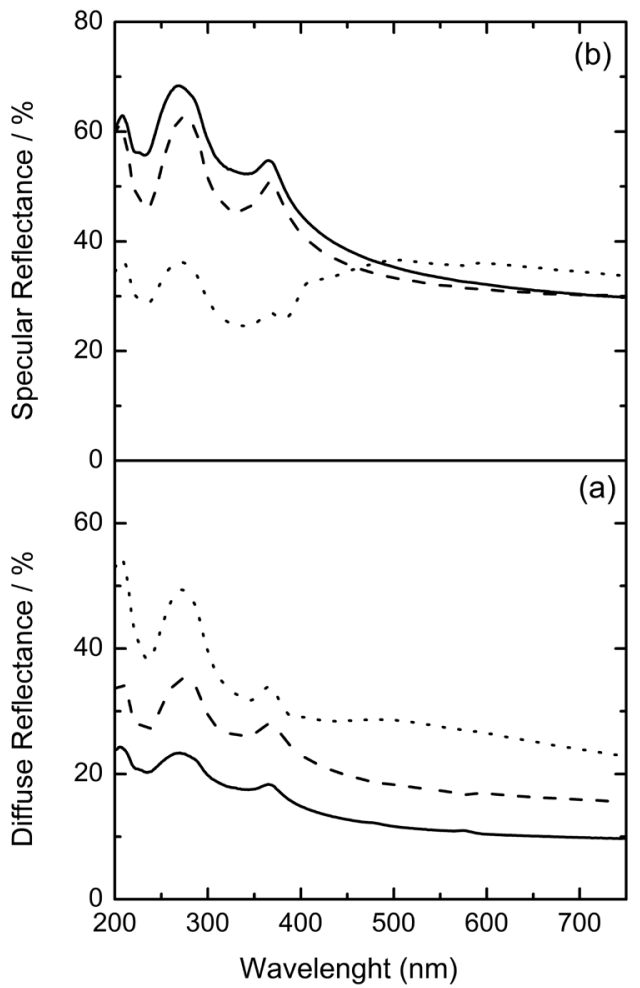

Figure 4: Reflectance of the modified silicon substrate with AuNPs derived from experiment 9 (Table V), at different times. (Solid Line) Si-H Surface; (Dashed Line) SiO2 surface; (Dolted Line) Si-Au NPs surface; Si a) Diffuse Reflectance, and b) Specular Reflectance. Deposition time: 10 minutes.
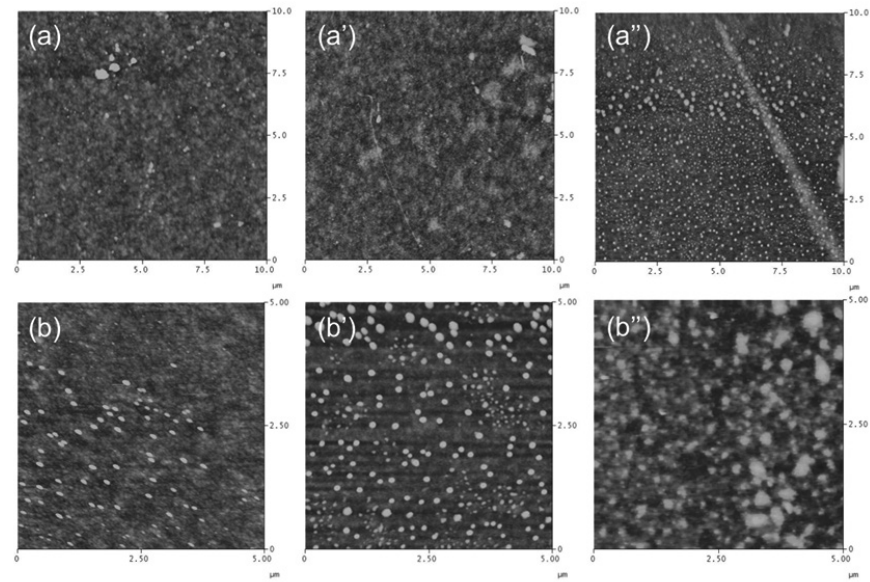

Figure 5: Ex-Situ AFM Images of AuNPs deposited at $40 \mathrm{~V}$ on p-Si at different times: Left (1 min); Center (5 min); Right (10 min). Top (AuNPs from Exp. 1); Bottom (AuNPs from Exp. 5).

Figure 5 shows the formation of AuNPs clusters of different sizes (AuNPs agglomerates), which were deposited on $\mathrm{p}$-Si at 3 different times: 1,5 and 10 minutes. When smaller AuNPs were used (above figures), a greater surface homogeneity was observed, which increases with deposition time, with well- defined clusters that are separate from their closest neighbors. On the other hand, for larger AuNPs deposits (Figures below), an agglomeration of the particles was produced when the deposition time increased. Furthermore, for 1 and 5 minutes of deposition, isolated particles were observed on the substrate surface, while at more than 10 minutes, large clusters could be observed with clear signs of coalescence ${ }^{22,39}$. Afterward, a section analysis was carried out to estimate the size of the AuNP clusters deposited on the p-Si. The values are summarized in Table VI.

Table VI: Average size of the AuNP clusters obtained through section analysis of the AFM images.

\begin{tabular}{|c|c|c|c|}
\hline $\begin{array}{c}\text { Experiment/ } \\
\text { Deposition time }\end{array}$ & $1 \mathrm{~min}$. & $5 \mathrm{~min}$. & $10 \mathrm{~min}$. \\
\hline Exp 1 & $38 \mathrm{~nm}$ & $88 \mathrm{~nm}$ & $98 \mathrm{~nm}$ \\
\hline Exp 5 & $68 \mathrm{~nm}$ & $127 \mathrm{~nm}$ & $169 \mathrm{~nm}$ \\
\hline
\end{tabular}

According to the data presented in Table VI, it is evident that a correlation exists with the values obtained by experiment design. In experiment 1 , smaller sizes were obtained, and for short deposition times, the agglomeration of a couple of AuNPs was produced, increasing to 5 particles agglomerated at 10 minutes of deposition. In turn, for experiment 5 (diameter of $64 \mathrm{~nm}$ according to equation (1) and Table II), at short times would be observed the deposition of 1 particle isolated from each other, increasing to 3 in 10 minutes of deposition.

Finally, a correlation in the morphology obtained between TEM and AFM analysis could be observed. Preferential morphology corresponding to spheres of AuNPs was observed. Other authors obtained similar results, however there are different shapes known ${ }^{40-43}$. On the other hand, a correlation between sizes estimated with equation (1) using the maximum of wavelength absorption, and observation by means morphology analysis (TEM y AFM) could be observed. According to these results, we can confirm that the model obtained from the experimental design allows for the prediction of the $\lambda_{\text {abs }}$ with a margin of error of approximately $5 \%$, which predicts the sizes of the AuNPs produced. In fact, using these values in widely used models as presented in equation (1) for size estimation was further verified by TEM and AFM.

\section{CONCLUSIONS}

According to the results obtained in this study, it was possible to observe that in the practiced conditions in the AuNPs synthesis, the stirring rate in the reaction was not a significant variable. On the other hand, an increase in both the reductant concentration and the temperature produced AuNPs of smaller size, which was associated with the generation of a greater quantity of growth nuclei. The positioning of the AuNPs through an irreversible electrophoretic method allowed for modified p-Si surfaces to be obtained with AuNPs whose surface density is a function of electrolysis time. Finally, a comparison of AuNPs sizes was possible using, on one hand, the $\lambda_{\text {abs }}$ values and the model proposed by Haiss in the equation (1), and comparing them to the measurements of the colloidal AuNPs and deposited on the substrate using TEM and AFM, respectively. According to these results, the use of this model is adequate for fine-tuning the experimental variables in the synthesis process for AuNPs with the absorption wavelength (which has a narrow relation to its size); with this it is possible to obtain particles according to the requirements set forth in previous research.

\section{ACKNOWLEDGMENTS}

We acknowledge the financial support from FONDECYT, Chile, (Grant No. 1150775) and the Department of Research and Innovation at the Pontificia Universidad Católica de Valparaíso (Grant No. 125.797/2015 DII-PUCV). E. Navarrete, J. Román and V. Rojas would like to acknowledge the kind support from the doctoral scholarship by CONICYT.

\section{REFERENCES}

1. B. Juárez, An. Quím. 107, 229, (2011).

2. D. Huang, F. Liao, S. Molesa, D. Redinger, V. Subramanian, J. Electrochem. Soc. 150, G412, (2003).

3. M. E. Ali, U. Hashim, S. Mustafa, Y. B. Che Man, Kh. Islam, J. Nanomater. (2012) doi:10.1155/2012/103607.

4. R. Zanella, Mundo Nano, 5, 69, (2012).

5. K. R. Brown, M. J. Natan. Langmuir. 14, 726, (1998). 
6. Y. Ohko, T. Tatsuma, T. Fujii, K. Naoi, C. Niwa, Y. Kubota, A. Fujishima,. Nat. Mater. 2, 20, (2003).

7. S. Martínez, T. Serrano, I. Gómez, A. Hernández, Bol. Soc. Esp. Ceram. $\mathrm{V}, \mathbf{4 6}, 97,(2007)$

8. D. Beer, P. Gale, Angew, Chem. Int. Engl. 40, 486, (2001).

9. J. Lehn, Supramolecular Chemistry: Concepts and perspectives, VCH, Weinheim. 1995

10. M. Warner, S. Reed, J. Hutchison, Chem. Mater. 12, 3316, (2000).

11. S. Galvagno, G. Parravano, J. Catal. 55, 178, (1978).

12. A. Alivisatos, K. Johnson, X. Peng, T. Wislon, C. Loneth, M. Bruchez, P. Schultz. Nature. 382, 609, (1996).

13. T. Taton, R. Mucic, C. Mirkin, R. Letsinger, J. Am. Chem. Soc. 122, 6305 , (2000).

14. G. Mie, Ann. Phys. 3, 377, (1908).

15. S. Chen, K. Huang, Langmuir. 16, 2014, (2000).

16. J. Kulys, R. Stupak, The Open Science Journal. 2, 34, (2008).

17. Z. JingJing, Z. JunJie. Sci. China Ser. B-Chem. 52, 815, (2009).

18. J. Pingarrón, P. Yáñez-Sedeño, A. González-Cortés. Electrochimica Acta. 53, 5848, (2008).

19. J. Jia, B. Wang, A. Wu, G. Cheng, Z. Li, S. Dong. Anal. Chem. 74, 2217, (2002).

20. H. Cai, Y. Wang, P. He, Y. Fang. Analytica Chimica Acta. 469, 165, (2002).

21. J. Turkevich. Gold Bull. 18, 125, (1985).

22. R. C. Bailey, K. J. Stevenson, J. T. Hupp. Adv. Mater. 12, 1930, (2000).

23. D. Buttard, F. Oelher, T. David. Nanoscale Res. Lett. 6, 580, (2011).

24. X. Lu, H. Tuan, B. A. Korgel, Y. Xia. 14, 1584, (2008).

25. J. Turkevich. Gold Bull. 18, 86, (1985).

26. J. Turkevich, P. C. Stevenson, J. Hillier. J. Discuss. Faraday Soc. 11, 55, (1951).
27. G. Frens, Nat. Phys. Sci. 241, 20, (1973).

28. D. A. Skoog, D. M. West. Fundamentals of analytical chemistry. 1963 Holt, Rinehart and Winston, Inc., USA.

29. F. Paneth. Phys Z, 15, 924, (1914).

30. K. Fajans, K. von Beckerath. Z. Phys. Chem. 97, 478, (1921).

31. Z. Adamczyk. Adv. Colloid Interface Sci. 100/102, 267, (2003).

32. E. J. W. Vervey, J. T. G. Overbeek. Theory of the stability of lyophobic colloids. 1948, Elsevier, Amsterdam, New York, republished by Dover Publ. Inc., Mineola, 1999.

33. G. Sonavane, K. Tomoda, K. Makino. Colloids and Surfaces B: Biointerfaces. 66, 274, (2008)

34. D. Kumar, B. J. Meenan, I. Mutreja, Raechelle D’Sa, D. Dixon. Int. J. Nanosci. 11, 1250023, (2012).

35. S. Honary, P. Ebrahimi, M. Ghasemitabar. Trop. J. Pharm. Res. 12, 295, (2013).

36. W. Haiss, N. T.K. Thanh, J. Aveyard. Anal. Chem. 79, 4215, (2007).

37. U. Pahk, S. Chongsawangvirod, E. A. Irene. J. Electrochem. Soc. 138, 308, (1991).

38. H. M. Branz, V. E. Yost, S. Ward, K. M. Jones. Appl. Phys. Lett. 94, 231121, (2009).

39. G. Chang, H. Shu, Kai Ji, M. Oyama, X. Liu, Y. He. Appl. Surf. Sci. 288, $524,(2014)$.

40. D. The Nguyen, D. Kim, M. Gi So b, Kyo-Seon Kim Adv. Powder Tech. 21, 111, (2010).

41. W. Patungwasa, J. H. Hodak, Mat. Chem. Phys. 108, 45, (2008)

42. D. Philip, Spectrochim. Acta A. 71, 80, (2008).

43. Z. Liu, Y. Zu, S. Guo, Appl. Surf. Sci. 255, 5827, (2009). 